\title{
PSICÓLOGOS(AS) ESCOLARES, DIVERSIDADE SEXUAL E ESCOLA: UM ESTUDO BRASIL/PORTUGAL
}

\author{
PSICÓLOGOS ESCOLARES, LA DIVERSIDAD SEXUAL Y LA ESCUELA: UN \\ ESTUDIO DEL BRASIL/PORTUGAL
}

\author{
PSYCHOLOGISTS SCHOOL, SEXUAL DIVERSITY AND SCHOOL: A STUDY \\ BRAZIL/PORTUGAL
}

\author{
Carmedite SILVA ${ }^{1}$ \\ Sara BAHIA ${ }^{2}$
}

RESUMO: Este artigo apresenta dados preliminares de pesquisa qualitativa/exploratória realizada entre dezembro de 2013 e março de 2014, no âmbito do doutorado em curso na Universidade de Lisboa/Portugal. Teve objetivo de caracterizar a atuação de Psicólogas (os) escolares no Brasil e Portugal frente às questões relativas à diversidade sexual no contexto escolar. Para tanto, utilizou-se a entrevista semiestruturada como técnica de coleta de dados. Através da Análise de Conteúdo, os resultados apontam que, embora as participantes ressaltem a importante contribuição da Psicologia para a superação de preconceitos e discriminações ainda persistentes no espaço escolar, situações dificultam a atuação: falta de autonomia para propor intervenções devido a pouca importância dada pela escola em relação a problematizações de temas ligados à questão; as inúmeras demandas da escola; não se sentem suficientemente preparadas devido a pouca ou nenhuma informação recebida ao longo da formação universitária e suas próprias crenças e valores. Daí decorre a importância de pesquisas que possam contribuir para a sensibilização de psicólogas (os) sobre às questões relativas à diversidade sexual e os efeitos destas na constituição dos sujeitos notadamente no espaço escolar onde são relatadas situações de discriminações e preconceitos.

PALAVRAS-CHAVE: Psicólogos Escolares. Diversidade sexual. Escola.

RESUMEN: Este artículo presenta losdatos preliminares de lainvestigacióncualitativa / exploratoria realizada desdediciembre 2013 hasta marzo 2014, enel curso de doctoradoenlaUniversidad de Lisboa / Portugal. Su objetivo era caracterizar eldesempeño de las(los) psicólogas(os) escolares en Brasil y Portugal frente alascuestiones relacionadas conladiversidad sexual enel contexto escolar. Por lo tanto, hemos utilizado las entrevistas semiestructuradas como una técnica de recolección de datos. A través de análisis de contenido, los resultados muestran que, aunquelos participantes destacanla importante contribuciónde lapsicología para superar loprejuicio yladiscriminacióntodavía persistentes enlaescuela, haysituacionesque

\footnotetext{
${ }^{1}$ Doutoranda em Psicologia da Educação pela Faculdade de Psicologia da Universidade de Lisboa. Email: carmedite@hotmail.com;

2 Orientadora $\operatorname{Prof}^{\mathrm{a}} \operatorname{Dr}^{\mathrm{a}}$ da Faculdade de Psicologia da Universidade de Lisboa. Email: sarabahias@gmail.com.
} 
dificultanlaactuación:falta de autonomía para proponer intervenciones debido a lapocaimportancia dada por laescuela a lasproblematizacionesde lostemas vinculados a lacuestión; numerosas demandas de laescuela; no se sientenlo suficientemente preparadasdebido a lapoca o ningunainformaciónrecibida a lo largo de laformaciónuniversitaria y a sus propiascreencias y valores.De ahí se desprende laimportancia de investigaciones que puedan contribuir a lasensibilización de psicólogas (os) sobre lascuestiones relativas a ladiversidad sexual y losefectos de estas enlaconstitución de lossujetos, principalmente enelespacio escolar donde se reportaronsituaciones de discriminación y prejuicio.

PALABRAS CLAVE: Los psicólogos escolares, ladiversidad sexual, escuela.

ABSTRACT: This article goal to come up with preliminary data from qualitative / exploratory research fulfilled between December 2013 and March 2014, inserted in the doctoral course in the University of Lisbon / Portugal. It aimed to characterize the performance of Psychologists school in Brazil and Portugal, facing the issues related to sexual diversity in the school context. For this was used the semi-structured interviews as a data collection technique. Through the content analysis results indicate that in spite of the participants highlight the important contribution that psychology can and should take forward the issues surrounding sexual diversity notably to overcome prejudice and discrimination that still persist in the school environment, some situations make it difficult to action: lack of incentive to propose interventions because of little importance given from school about to questioning issues related to this subject; the numerous demands of school; They do not feel sufficiently prepared due to little or no information received over the university and their own beliefs and values. Hence the importance of research to contribute to the awareness of psychologists about the issues of sexual diversity and the effects of the constitution of subjects especially at school where situations of discrimination and prejudice are reported.

KEYWORDS: School Psychologists. Sexual Diversity. School.

\section{Introdução}

A escola é um importante espaço de reflexões e ações fundamentais para a promoção de valores democráticos, de respeito ao outro e transformação social, no entanto, preconceitos e discriminações ainda são relatadas em relação à diversidade sexual, aqui entendida, como as diversas possibilidades de vivenciar a sexualidade, principalmente as orientações sexuais e identidades de gênero que fogem aos padrões heteronormativos. Para além das dificuldades de aceitação e convivência com a pluralidade sexual, "a sexualidade como um todo é exorcizada da vida escolar, sendo homossexuais considerados "personas non gratas" (CORRÊA, 2003, p. 133)

Mott (2006) aponta para um movimento de despatologização da homossexualidade e de defesa dos direitos humanos das minorias sexuais ao destacar o 
fato de pesquisas internacionais em diversas áreas demonstrarem que a homossexualidade não se constitui em perversão, distúrbio ou doença.

Alinham com esta constatação importantes entidades a exemplo da Associação Psiquiátrica Americana em 1973, Associação de Psicologia Americana, em 1975. Do mesmo modo que a Organização Mundial de Saúde, desde 1992, exclui o código 302.0 da Classificação Internacional de Doenças deixando a homossexualidade de ser considerada "desvio e transtorno sexual", também a terceira edição do Manual Diagnóstico e Estatístico dos Distúrbios Mentais retira a homossexualidade da classificação de parafilia, em 1987. No Brasil, em 1999, o Conselho Federal de Psicologia lança a Resolução 01/1999, que estabelece normas de atuação para os psicólogos em relação à questão da Orientação Sexual (CFP, 1999)

Mesmo assim, muitas das formas com as quais a escola lida com as situações que envolvem questões relativas à diversidade sexual e, notadamente, a homossexualidade

são procedimentos que ferem a dignidade do outro provocando sofrimentos e revoltas, pois "estão ancorados em "padrões culturais" que cultivam simbólica e explicitamente hierarquias e moralismos em nome da virilidade, da masculinidade e da rigidez que codifica uma determinada vivência da sexualidade como a normal, a consentida" (ABRAMOVAY; CASTRO; SILVA, 2004, p. 278).

Esta realidade é percebida também em Portugal. Segundo o Relatório do Observatório de Educação LGBT da Rede Ex-Aequo (2012), que é uma associação de jovens lésbicas, gays, bissexuais, transgêneros e simpatizantes, 85\% dos jovens homo ou bissexuais dizem ter ouvido comentários homofóbicos na escola. Mais recentemente, no relatório de 2014 (embora a amostra seja pequena), constata-se que as queixas se agravam em $25 \%$ no que se refere à tentativa de suicídio e de abandono escolar.

Também nos resultados de estudos realizados pela Comissão Europeia (2009), citados por Gatto e Fontaine (2012), cerca de 60\% das (os) portuguesas (es) consideram que a orientação não heterossexual é um fator de discriminação comum no país, sendo o valor médio para a Europa de 47\%. Importante ressaltar, conforme Fernandes (2010), que avanços em relação à legislação voltada para a garantia de direitos da população LGBT (Lésbicas, Gays, Bissexuais, Travestis, Transexuais e Transgêneros) e de políticas de combate à homofobia tem sido implementadas em Portugal. 
Estas realidades exigem respostas das (os) profissionais que atuam na escola, entre estes as (os) Psicólogas (os) Escolares que, para Carita (2012), são todas (os) que tem suas atividades desenvolvidas na escola e que, segundo o Conselho Federal de Psicologia (Brasil, 1999) podem e deveriam contribuir com seu conhecimento para o esclarecimento sobre as questões da sexualidade, permitindo a superação de preconceitos e discriminações não devendo manter posicionamentos teóricos que perpetuem o modelo de exclusão.

\title{
Psicologia e Diversidade Sexual
}

A Psicologia, como área do conhecimento que produz saberes acerca da sexualidade humana, tem-se posicionado frente à questão da diversidade sexual, notadamente a partir da década de 1970, época em que, para Toneli (2008), sexo e sexualidade tornam-se objetos de pesquisa e discussões teóricas em diversas áreas do conhecimento.

Mas, para Foucault (2002), esses saberes se constituíram para dar conta da normalidade e se esforçam por controlar o que se opõe a isso:

\begin{abstract}
sem forçar nenhuma exatidão, pode-se dizer que a psicologia contemporânea é, em sua origem, uma análise do anormal, do patológico, do conflituoso, uma reflexão das contradições do homem consigo mesmo. Se ela se tornou uma psicologia do normal, do adaptativo, do organizado, é de um segundo modo, como que um esforço por dominar estas contradições. (FOUCAULT, 2002, p. 135)
\end{abstract}

Essa perspectiva é compartilhada por Guareschi e Hüning (2005), ao apontarem que as Psicologias tradicionais têm se afirmado, constantemente, como referência a estas normas, buscando assim a correção dos sujeitos através das suas intervenções. Nesse sentido, aqueles que escapam aos regulamentos impostos pela lógica heterossexual tornam-se incompreensíveis, anormais.

Para Louro (2010), essa situação suscita a necessidade de reflexão por parte da Psicologia, na medida em que, ao longo de sua história, tem produzido discursos que contribuem para construção e manutenção do preconceito em relação à homossexualidade, mas que, por outro lado, contemporiza a autora, também tem contribuído para seu enfrentamento e superação.

O senso comum indica a(o) psicóloga(o) como a(o) profissional mais preparada(o) para trabalhar com a sexualidade. Segundo Paiva (2008), raramente, 
entretanto, são formadas (os) para lidar com a vida sexual em contextos que não sejam clínicos, sendo necessário que as psicologias e o ensino de Psicologia redescubram a sexualidade.

A autora chama a atenção para o fato de que sexo e sexualidade fazem parte da vida cotidiana das pessoas e que a formação que é dada nas universidades não prepara as (os) psicólogas (os) para lidarem com essas questões em seus diversos contextos quer seja na saúde, na escola, no ambiente de trabalho, na comunidade, portanto, para além da perspectiva centrada na clínica.

Diante do exposto, este artigo pretende apresentar os dados preliminares do estudo exploratório cujo objetivo foi caracterizar a atuação de Psicólogas escolares que atuam no Brasil e em Portugal em relação as questões da diversidade sexual no contexto escolar. Realizada entre dezembro de 2013 e março de 2014, foi submetida e aprovada pela Comissão de Deontologia da Faculdade de Psicologia da Universidade de Lisboa.

\section{Desenho e Construção do Estudo}

Este estudo foi baseado em pesquisa de abordagem qualitativa/exploratória que segundo Gil (2008) visa proporcionar maior familiaridade com o problema.

Para o processo de coleta de dados foi utilizada a entrevista semiestruturada (MINAYO, 1998) elaborada especificamente para este fim. O guião de entrevista está orientado para quatro objetivos: conhecer em que consiste o trabalho das psicólogas na escola; identificar como a escola dialoga com temas ligados à diversidade sexual; saber quais e que tipos de conhecimentos as psicólogas possuem em relação a temas relacionados à questão; caracterizar a atuação das profissionais frente às situações relacionadas à diversidade sexual na escola. Para cada objetivo foram elaboradas três ou mais questões.

Participaram da pesquisa 5 psicólogas escolares, todas do sexo feminino sendo 3 brasileiras e 2 portuguesas. No primeiro momento, encaminhou-se e-mail explicativo dos objetivos da pesquisa e solicitação da participação na pesquisa. Em caso afirmativo, dias e horários foram agendados. 
As entrevistadas inserem-se na faixa etária de 32 a 57 anos e atuam no ensino fundamental $^{3}$. O tempo de experiência profissional variou de 6 a 18 anos; todas exercem suas funções em escolas privadas e possuem pós-graduação em Educação ou em Clínica. Quanto ao quesito cor/raça/etnia, três declararam-se negras e duas brancas. Em relação à orientação sexual, apenas uma mencionou ser homossexual e, no que diz respeito à religião, três católicas e duas evangélicas.

A escolha da amostra foi feita por conveniência, levando-se em consideração a disponibilidade por parte das entrevistadas. Os nomes das profissionais foram omitidos para preservar o sigilo das declarações e impossibilitar a identificação, sendo apresentadas (os) pelas siglas: PE1, PE2, PE3, PE4 e PE5.

Para a análise dos dados que se apresentam neste artigo, foi utilizada a técnica da Análise de Conteúdo que segundo Bardin (2009) é um conjunto de técnicas de análise das comunicações visando obter por procedimentos sistemáticos e objetivos de descrição do conteúdo das mensagens indicadores (quantitativos ou não) que permitam a inferência de conhecimentos relativos às condições de produção/recepção (variáveis inferidas) destas mensagens.

\section{Resultados e Discussões}

Após a análise dos dados, chegou-se as seguintes categorias: Exercício profissional; Escola e diversidade sexual; Conhecimento sobre diversidade sexual e atuação em relação a diversidade sexual.

\footnotetext{
${ }^{3}$ Ensino Fundamental é o nome dado a uma das etapas da educação básica no Brasil, com duração de nove anos é obrigatória para todas as crianças com idade entre 6 e 14 anos, correspondente ao Ensino Básico em Portugal.
} 
Tabela 1- Síntese da Análise de Conteúdo realizada para as quatro categorias

\begin{tabular}{|c|c|c|}
\hline Categorias & Subcategoria & Unidade de contexto \\
\hline \multirow[t]{2}{*}{$\begin{array}{l}\text { a) O trabalho na } \\
\text { escola }\end{array}$} & Em que consiste o trabalho & $\begin{array}{l}\text { Há uma exigência de uma atuação diversificada, são } \\
\text { demandas variadas. Realizo avaliação e } \\
\text { acompanhamento Psicopedagógico de estudantes; } \\
\text { orientação a pais; assessoria a equipe da escola. } \\
\text { (professores, direção, funcionários, coordenação } \\
\text { pedagógica); participo das reuniões; faço } \\
\text { encaminhamentos quando necessários, realizo } \\
\text { atendimento individual... (PE3) }\end{array}$ \\
\hline & Desafios e enfrentamentos & $\begin{array}{l}\text { Quando apareceu um problema, tive que falar sobre } \\
\text { homossexualidade e sobre diversidade, pois temos um } \\
\text { aluno de } 11 \text { anos que é claramente homossexual. São } \\
\text { tantas as demandas. Realmente são grandes os } \\
\text { desafios na escola, esta questão da homossexualidade } \\
\text { é realmente um grande desafio... PE2) }\end{array}$ \\
\hline \multirow[t]{3}{*}{$\begin{array}{l}\text { b)Escola e } \\
\text { diversidade sexual }\end{array}$} & Tabus e preconceitos & $\begin{array}{l}\text { Os preconceitos, as crenças, os valores que são } \\
\text { reproduzidos na escola acabam sendo muito fortes e } \\
\text { interferem na nossa prática. Olha, a verdade é que } \\
\text { essa questão é tabu na escola sim! E fica difícil você } \\
\text { remar contra a maré. PE3 }\end{array}$ \\
\hline & Pouca importância dada a questão & $\begin{array}{l}\text { No geral esse tema da homossexualidade é difícil } \\
\text { trabalhar na escola, os professores, a própria direção, } \\
\text { a família, evitam trazer essas questões, tipo assim, é } \\
\text { melhor que não apareça, entende? PE4 }\end{array}$ \\
\hline & Falta de autonomia. & $\begin{array}{l}\text { (...) na escola não tenho autonomia para trabalhar } \\
\text { certas questões, primeiro tenho que ficar "apagando } \\
\text { fogo" com tanta coisa para fazer, já até propus um } \\
\text { projeto para falar sobre diversidade sexual, mas aí } \\
\text { tem a família que não quer, a escola pressiona, os } \\
\text { professores pressionam... PE5 }\end{array}$ \\
\hline \multirow{2}{*}{$\begin{array}{l}\text { c)Conhecimento } \\
\text { sobre diversidade } \\
\text { sexual }\end{array}$} & $\begin{array}{l}\text { Conhecimentos sobre diversidade } \\
\text { sexual }\end{array}$ & $\begin{array}{l}\text { Conheço pouco, aliás, que documentos a Psicologia } \\
\text { têm produzido sobre essas questões? (PE3) }\end{array}$ \\
\hline & Formação universitária deficitária & $\begin{array}{l}\text {...As pessoas têm a fantasia que Psicóloga conhece } \\
\text { sobre a sexualidade, uma fantasia mesmo, pois na } \\
\text { nossa formação na universidade não somos } \\
\text { preparadas para lidar com essas questões a gente } \\
\text { acaba por continuar a ver a questão da perversão, da } \\
\text { patologia. (PE2) }\end{array}$ \\
\hline \multirow[t]{3}{*}{$\begin{array}{l}\text { d)Atuação em } \\
\text { relação a } \\
\text { diversidade sexual }\end{array}$} & $\begin{array}{l}\text { Falta de atuação específica em relação } \\
\text { à diversidade sexual }\end{array}$ & $\begin{array}{l}\text { "não tenho uma atuação voltada para isso, tenho que } \\
\text { trabalhar mais as questões de aprendizagem e tudo } \\
\text { que envolve isso. Na verdade, quando aconteceu a } \\
\text { questão das duas meninas que se beijaram no pátio da } \\
\text { escola não senti uma atuação específica como } \\
\text { Psicóloga, acabou que a direção tomou a frente...." }\end{array}$ \\
\hline & Crenças e valores & $\begin{array}{l}\text { Mas sabe de uma coisa? Acho que acaba tudo numa } \\
\text { questão, no preconceito, nas crenças, nos valores } \\
\text { religiosos, nas opiniões, as pessoas são } \\
\text { preconceituosas mesmo sendo psicólogo, tem que } \\
\text { trabalhar também o próprio profissional, e junta com } \\
\text { a faculdade que não discute isso.... PE4 }\end{array}$ \\
\hline & Atuação equivocada & $\begin{array}{l}\text { O menino era todo "afeminado", tive que chamar para } \\
\text { conversar com ele, falar um pouco sobre esse "jeito" } \\
\text { dele, fiz uma escuta e trabalhei essa necessidade dele } \\
\text { de se expor as brincadeiras dos colegas, mostrar pra } \\
\text { ele que não tem nada de errado na opção sexual dele, } \\
\text { mas ele devia se preservar mais, não demonstrar tanto } \\
\text { os trejeitos, desnecessário isso. PE4 }\end{array}$ \\
\hline
\end{tabular}


Através da tabela acima apresentada, construída a partir dos objetivos traçados, do guião de entrevista e dos recortes do discurso das entrevistadas, podemos estabelecer inferências que nos auxiliam na análise dos dados, entre as quais se pode destacar:

\section{a) O trabalho na Escola}

Com este tema buscou-se conhecer a dinâmica do trabalho destas profissionais na escola. Neste sentido, destaca-se o fato de que, tanto as psicólogas brasileiras quanto portuguesas enfrentam inúmeras e variadas demandas. As entrevistadas percebem que lidar com questões relativas a diversidade sexual se constitui em grande desafio na escola, um dos motivos pelos quais estas questões acabarem por não serem privilegiadas na rotina das atividades, sendo tratadas apenas na medida em que há alguma questão específica.

\section{b) Escola e Diversidade Sexual}

Este tema se refere as percepções das psicólogas sobre como a escola lida com questões relativas à diversidade sexual. A totalidade das entrevistadas admite que estas situações acontecem na escola conforme coloca PE2, "Acho difícil hoje em dia não ter esses acontecimentos na escola. Recentemente tivemos sérios problemas por conta de um menino de 8 anos que apresenta trejeitos femininos." No entanto, nas escolas em que trabalham, segundo as entrevistadas, estas temáticas são polêmicas pois não envolvem somente discussões com base em conhecimentos científicos, mas também crenças, valores, saberes especulativos, conservadores, imersos em preconceitos. Estes tabus conforme as profissionais, fazem com que a escola dê pouca importância às questões ligadas à diversidade sexual e até mesmo busque invisibilizá-las.

Estas percepções remetem à constatação de Foucault (1980) de que a escola é o espaço onde as mulheres, os negros e os homossexuais terão direitos, desde que se comportem e aceitem todas as visões do mundo, as posturas e as condutas dos homens brancos heterossexuais. Neste contexto, as psicólogas entrevistadas apontam, também, a falta de autonomia para propor ações que visem à reflexão destas questões

Portanto, alinhando ainda ao pensamento de Foucault (1980), a "colocação do sexo em discurso" no espaço escolar continua a ser uma região de "tato e discrição". Embora, paradoxalmente, não cessem de proliferar os discursos que buscam trazer a questão à baila, a exemplo dos PCN's, que trazem os temas transversais, como também 
programas como Brasil sem Homofobia, Projeto Escola Sem Homofobia, os movimentos sociais, entre outros.

\section{c) Conhecimento sobre Diversidade Sexual}

Neste tema, a ausência de disciplinas e discussões ao longo da formação universitária em relação à diversidade sexual se revela categoria importante para as profissionais de ambos os países. Esta carência, no entendimento das entrevistadas, pode reforçar práticas que promovam a manutenção e reprodução de situações de preconceitos e discriminações frente às expressões da sexualidade ditas não normativas na escola.

As falas vão de encontro a Santos, Costa e Nardi (2011), quando colocam que a formação em psicologia é tradicionalmente marcada pela patologização das performances de gênero e das sexualidades que fogem à matriz heteronormativa.

A ausência da discussão sobre a diversidade sexual na formação das (os) futuras (os) profissionais reproduz e reforça as condições que permitem a existência e a continuidade da homofobia, ao passo que "sua denúncia e combate criarão condições para uma política educacional antidiscriminatória” (RIOS; SANTOS, 2009 p. 152).

\section{d) Atuação em Relação a Diversidade Sexual}

Com este tema, buscou-se caracterizar a atuação das psicólogas em relação à diversidade sexual. As entrevistadas brasileiras e portuguesas revelam não terem intervenções específicas voltadas às situações que envolvem à diversidade sexual na escola, ressaltam que o sistema de crenças e valores das próprias profissionais impactam no desenvolvimento destas ações e isto pode resultar em reprodução de práticas discriminatórias e preconceituosas.

Este contexto nos leva a pensar que, embora a condição de patologia da homossexualidade tenha sido repensada através dos decretos e resoluções de importantes entidades médicas e psicológicas, segundo Leal (2004), não tem sido incorporado por todas (os) as (os) profissionais que atuam na Psicologia.

Ainda existem demonstrações de atitudes preconceituosas a exemplo dos estudos de Mohr e Weiner (2006) e Moita (2006), realizados com Psicólogas (os) que atuam na clínica, apontam que as orientações homossexual e bissexual ainda são consideradas por algumas (uns) psicoterapeutas como um sinal de psicopatologia, ou seja, a 
orientação sexual do cliente influencia os julgamentos do profissional relativamente ao tratamento.

Corrobora com essa posição a análise de Nogueira (2010), ressalta que discursos atuais da ciência psicológica tem, por um lado, afirmado que a homossexualidade é uma expressão natural da atração erótica e dos relacionamentos, uma orientação viável e saudável, mas, por outro lado, existem ainda preconceitos e desinformação persistentes sobre a homossexualidade que impactam na prática de Psicólogas (os) em suas variadas áreas. A autora sugere que, no que se refere à diversidade sexual, a Psicologia permanece envolta em contradições, em que pese os avanços nos últimos anos.

Estes posicionamentos não encontram respaldo nas pautas éticas que regulam o exercício profissional de Psicólogas (os) a partir dos seus Códigos de Ética, estes, alertam para o fato de que no exercício profissional deve-se tomar cuidado para que os preconceitos potenciais, os limites de competência e as limitações dos conhecimentos das (os) profissionais não as (os) levem ao envolvimento e à tolerância com práticas injustas.

\section{Considerações Finais}

Diante dos dados e análises apresentadas é possível observar que são grandes os desafios postos as (os) psicólogas (os) escolares brasileiras (os) e portuguesas (es) frente a questão da diversidade sexual na escola onde ainda persistem situações de preconceitos e discriminações.

Neste contexto, destacam-se falas que revelam condições diversas que se interpõem à uma prática voltada para estas questões: falta de estímulo para propor intervenções devido a pouca importância dada pela escola em relação a problematizações de temas ligados à questão; as inúmeras demandas da escola; não se sentem suficientemente preparadas devido a pouca ou nenhuma informação recebida ao longo da formação universitária e suas próprias crenças e valores.

Por um lado, a necessidade de superação de um saber que se constituiu no campo da normalidade e que tem a heterossexualidade como modelo. Pelo outro, o desafio de exercer uma psicologia escolar comprometida com a superação de discursos que 
padronizam, desqualificam, negam e marginalizam as diferentes expressões da sexualidade.

A pouca importância que a escola dá para temas que envolvem a diversidade sexual, os preconceitos, as crenças, os valores que lá são reproduzidos tornam os assuntos que se relacionam a esta temática questões delicadas e difíceis de trabalhar

A formação universitária deficitária, o fato de não se sentirem suficientemente preparadas para lidarem com estes assuntos devido a falta de disciplinas que tratem da temática são apontadas como importantes entraves para a atuação. As profissionais enfatizam a necessidade de componentes curriculares que contemplem essas discussões, possibilitando melhor qualificação que resulte em prática voltada para o enfrentamento de preconceitos e discriminações por orientação sexual na escola.

É certo que a atuação da(o) profissional da Psicologia no espaço escolar não pode ignorar quadros graves de exclusão social, que causam grandes sofrimentos psíquicos, para tanto também é necessário um posicionamento ético de superação de atitudes preconceituosas das próprias profissionais. Daí decorre a necessidade de que as(os) Psicólogas(os) tenham a consciência da responsabilidade das suas práticas, pois sem esta consciência, as (os) profissionais poderão lesar direitos fundamentais das pessoas e, no limite, colaborar para a negação de seu direito à vida. (MELLO e PATTO, 2008, p. 594).

Aspiramos pela construção de uma prática profissional comprometida social e politicamente com a sociedade e com uma Educação calcada nos direitos humanos e no respeito as diversidades.

\section{REFERÊNCIAS}

ABRAMOVAY, M., CASTRO, M. G., SILVA, L. B. Juventude e sexualidade. Edições UNESCO, Brasil, 2004.

BARDIN, L. Análise de conteúdo. Lisboa: Edições 70, 2009.

BRASIL, Conselho Federal de Psicologia. Resolução No 01/1999. Disponível em: < http://www.pol.org.br/pol/export/sites/default/pol/legislacao/legislacaoDocumentos/reso luca o1999_1.pdf>. Acesso em: 14 out. 2012

CARITA, A. Psicologia e psicólogos escolares: perfil e confrontos éticos. Lisboa: Edições Universitárias Lusófonas, 159 p., 2012. 
CONSELHO DA EUROPA. Discrimination on grounds of sexual orientation and gender identity in Europe. Council of Europe Publishing. 2011. Disponível em: <http://www.coe.int/t/ Commissioner/Source/LGBT/LGBTStudy2011_en.pdf>. Acesso em: 12 mar. 2013

CORRÊA, L. B. A exclusão branda do homossexual no ambiente escolar. (003) 153 f. Dissertação (Mestrado em Educação) - Faculdade de Educação, Universidade Federal do Rio Grande do Sul, Porto Alegre, 2003.

FERNANDES, F. As políticas anti-homofóbicas na União Europeia e suas fronteiras. (Plano de Estudos de Pós-Doutorado Programa CAPES-COFECUB). Disponível em: <http://nigs.paginas.ufsc.br/files/2012/01/plano_estudos_fbmf_CAPESCOFECUB_PD F-c\%C3\%B3pia.pdf>. Acesso em: 15 maio 2014.

FOUCAULT, M. A psicologia de 1850 a 1950 (Ditos e Escritos I - Problematização do sujeito: psicologia, psiquiatria e psicanálise). Rio de Janeiro: Forense Universitária, 2002.

FOUCAULT, M. História da sexualidade 1: A vontade de saber. 3. ed. Rio de Janeiro: Graal, 1980.

GATO, J.; FONTAINE, A. M. Atitudes face à diversidade sexual no contexto psicossocial, jurídico, da saúde e educativo. Exedra, v. 6, 81-103, 2012

GIL, A. C. Como elaborar projetos de pesquisa. 4. ed. São Paulo: Atlas, 2008

GOMES L. G. F. F. Novela e sociedade no Brasil. Niterói: EdUFF, 1988. 137p., 21 cm. (Coleção Antropologia e Ciência Política, 15).

GUARESCHI, N. M.; HÜNING, S. Efeito Foucault: desacomodar a psicologia. In GUARESCHI, M. N.; HÜNING, S. (Eds.), Foucault e a Psicologia (pp. 107-127). Porto Alegre: Abrapso Sul, 2005.

LEAL, I. Parentalidades. Questões de género e orientação sexual. In. CASCAIS, A. F. (Ed.), Indisciplinar a teoria: Estudos gays, lésbicos e queer (pp. 215-243). Lisboa: Fenda, 2004.

LOURO, G. L. Currículo, género e sexualidade: o "normal", o "diferente" e o "excêntrico". In G. L. Louro, J. F. Neckel, \& S. V. Goellner (Eds.), Corpo, género e sexualidade: um debate contemporâneo na educação. $5^{a}$ ed. Petrópolis, RJ: Vozes, 2010 .

MELLO, S. L. PATTO, M. H. S. Psicologia da violência ou violência da psicologia? Psicologia USP, v. 19, n. 4, 591-594, 2008.

MINAYO, M. C. S. (Org.). Pesquisa Social: teoria, método e criatividade. Petrópolis: Vozes, 1998.

MOHR, J. J.; WEINER J. L. Client sexual orientation and psychotherapists's clinical perceptions. In PAGE, E.; FIRENSTEIN, B. (Eds.). Current research on bisexuality: Identity, health and clinical attitudes. Symposium: American psychological Association 
meeting. New Orleans, LA, 2006.

MOITA, G. A patologia da diversidade sexual: homofobia no discurso de clínicos. Revista Crítica de Ciências Sociais, v. 76, 53-72, 2006.

MOTT, L. Homoafetividade e direitos humanos. Estudos Femininos, v. 14, n. 2, 509$521,2006$.

NOGUEIRA, C.; OLIVEIRA, J. M. Um olhar da psicologia feminista crítica sobre os direitos humanos de pessoas LGBT. In NOGUEIRA C.; OLIVEIRA, J. M. (Eds.), Estudo sobre a discriminação em função da orientação sexual e da identidade de género (pp. 9-17). Lisboa: Comissão para a Cidadania e a Igualdade de Género, 2010.

PAIVA, V. A psicologia redescobrirá a sexualidade?. Psicologia em Estudo, v. 13, n. 4, 641-651, 2008. Disponível em: <http://www.scielo.br/scielo.php?script=sci_arttext\&pid=S1413-

$73722008000400002 \& \operatorname{lng}=$ en\&tlng=pt. 10.1590/S1413-73722008000400002>. Acesso em: 24 maio 2013.

REDE EX-AEQUO. Observatório de Educação LGBT. Relatório bianual sobre discriminação em função da orientação sexual e/ou da identidade ou expressão de género no espaço escolar em Portugal, 2012. Disponível em: <http://www.rea.pt/imgs/uploads/doc-observatorio-educacao-2012.pdf>. Acesso em: 10 jan. 2013.

RIOS, R. R.; SANTOS, W. R. Diversidade sexual, educação e sociedade: reflexões a partir do Programa Nacional do Livro Didático. Revista Psicologia Política, v. 8, n. 16, 325-344, 2009. Disponível em: $<$ http://pepsic.bvsalud.org/scielo.php?script=sci_arttext\&pid=S1519-

549X2008000200010\&lng=pt\&tlng=pt>. Acesso em: 03 nov.2013

SANTOS, C. B.; COSTA, Â. B.; CARPENEDO, M.; NARDI, H. C. A diversidade sexual no ensino de Psicologia. O cinema como ferramenta de intervenção e pesquisa: Sexualidad, Salud y Sociedad (Rio de Janeiro), v. 7, 127-141, 2011. Disponível em: <http://www.scielo.br/scielo.php?script=sci_arttext\&pid=S198464872011000200006\&lng=en\&tlng=pt. 10.1590/S1984-64872011000200006>. Acesso em: 18 mar. 2013.

SANTOS, F. R. A colonização da terra do Tucujús. In: História do Amapá, 1. o grau. 2. ed. Macapá: Valcan, 1994.

TONELI, M. J. F. Diversidade sexual humana: notas para a discussão no âmbito da psicologia e dos direitos humanos. Psicologia Clínica, v. 20, n. 2, 61-73, 2008. 


\section{Como referenciar este artigo}

SILVA, Carmedite.; BAHIA, Sara. Psicólogos (as) escolares, diversidade sexual e escola: um estudo Brasil/Portugal. Revista Ibero-Americana de Estudos em Educação, Araraquara/SP, v. 11, n. esp. 3, p.1761-1774, 2016. Disponível em: <http://dx.doi.org/10.21723/riaee.v11.n.esp3.9070>. E-ISSN: 1982-5587.

Submetido em: agosto/2016

Aprovado em: novembro/2016 